Arq. Bras. Med. Vet. Zootec., v.56, n.1, p.1-6, 2004

\title{
Avaliação de vacinas contra Clostridium novyi tipo B
}

[Evaluation of vaccines against Clostridium novyi type B]

\author{
R.A.P. Nascimento ${ }^{1}$, F.C.F. Lobato $^{2}$, V.L.V. Abreu ${ }^{2}$, N.E. Martins $^{2}$, R.A. Assis ${ }^{2}$, M.B. Carvalho Filho ${ }^{1}$ \\ ${ }^{1}$ Laboratório Regional de Apoio Animal - LARA/MG \\ Caixa Postal 50 \\ 33600-000 - Pedro Leopoldo, MG \\ ${ }^{2}$ Escola de Veterinária da UFMG- Belo Horizonte
}

\section{RESUMO}

Avaliou-se a eficiência de 13 vacinas comerciais contra clostridioses que continham em sua composição Clostridium novyi tipo B, pela titulação de antitoxina alfa em soro de coelhos e de bovinos vacinados e pelo teste de desafio direto em cobaias. As vacinas codificadas como T1 e T10 apresentaram, em coelhos, títulos de antitoxina alfa de 8 e 12UI/ml respectivamente, superiores ao nível mínimo de teste de $3,5 \mathrm{UI} / \mathrm{ml}$, recomendado para controle desse produto, e as vacinas $\mathrm{T} 2$ e $\mathrm{T} 5$, títulos de 2 e $3 \mathrm{UI} / \mathrm{ml}$, respectivamente. As vacinas T1, T2, T5 e T10 apresentaram níveis de antitoxina alfa detectáveis em bovinos, mas somente T1 e T10 induziram títulos compatíveis com o nível de teste. Pelo método de desafio direto em cobaias, as vacinas T1, T2, T5, T10 e T11 atenderam aos requisitos, protegendo todos os animais desafiados. Em sua maioria, as vacinas comercializadas no Brasil contra Clostridium novyi tipo B foram ineficientes em estimular títulos sorológicos compatíveis com os níveis de teste recomendado para controle desse produto.

Palavras-chave: vacina, toxina, Clostridium novyi tipo B, hepatite necrótica infecciosa, clostridiose

\begin{abstract}
The antibody response to the Clostridium novyi type B alfa toxin component of 13 commercial vaccines (T1 to T13) and a standard toxoid was evaluated by the serum neutralization test with rabbit and cattle sera and by direct challenge of vaccinated guinea pig. T1 and T10 induced titles of C. novyi type B alfa antitoxin in rabbits, superior to the recommended minimum title of $3.5 \mathrm{IU} / \mathrm{ml}$, namely of 8 and $12 \mathrm{IU} / \mathrm{ml}$, respectively. T2 and T5 induced titles of 2 and $3 \mathrm{IU} / \mathrm{ml}$, respectively. These, plus $T 1$ and T10, were also the only vaccines which produced detectable antitoxin in bovine sera. T1, T2, T5 and T10, plus T11, were able to protect all the vaccinated guinea pigs at the challenge. Most of $\mathrm{C}$. novyi type B vaccines in Brazil was unable to induce the minimum antibody response recommended for approval of the product.
\end{abstract}

Keywords: vaccine, toxin, Clostridium novyi type B, infectious necrotic hepatitis, clostridiosis

\section{INTRODUÇÃO}

Clostridium novyi tipo B faz parte do quadro dos agentes etiológicos responsáveis pelas clostridioses. Como todo Clostridia, é ubiquitário, tem a propriedade de permanecer por longo período no solo na forma de esporos, e ao encontrar condições favoráveis, prolifera rapidamente e produz toxinas. Clostridium novyi tipo B é o agente da hepatite necrótica, também conhecida como moléstia negra dos ovinos. Nas regiões endêmicas, esporos podem estar presentes no fígado dos animais, principalmente de ovinos. Lesões focais no fígado, causadas por

Recebido para publicação em 8 de maio de 2003

Recebido para publicação, após modificações, em 1 de setembro de 2003

E-mail: ricardoaurelio@yahoo.com.br 
migração de formas imaturas de trematódeos hepáticos e pelo uso de quimioterápicos, favorecendo a germinação dos esporos e produção de toxinas, têm sido relatadas como prováveis fatores desencadeadores da hepatite necrótica (Uzal et al., 1996; Robles et al., 2000). Clostridium novyi tipo B está, também, associado à morte súbita (Sterne, Batty, 1978). Existem poucos relatos desse agente no Brasil. Apesar da elevada ocorrência de focos e de animais suspeitos de clostridioses, a maioria dos diagnósticos baseia-se em dados clínicos. Baldassi (1986) isolou bactérias do gênero Clostridium, de 118 amostras de espécimes clínicos de fígado, conteúdo ruminal e fezes. Seis foram classificadas por provas bioquímicas como Clostridium novyi, sem determinação do tipo envolvido.

A utilização de imunógenos tem reduzido, em grande parte, a mortalidade e conseqüentes perdas econômicas relacionadas às clostridioses. As vacinas comercializadas no Brasil são compostas de múltiplos antígenos. As normas para controle das vacinas estão definidas na legislação do Ministério de Agricultura e Abastecimento (MAPA; Brasil, 1997). Em relação ao Clostridium novyi tipo $\mathrm{B}$, exige-se nível mínimo de antitoxina alfa de $3,5 \mathrm{UI} / \mathrm{ml}$, determinado pela técnica de soroneutralização em camundongos, pela titulação de soros de coelhos vacinados (Brasil, 1997).

Na década de 90 a produção de 1 bilhão 193 milhões de doses de vacinas polivalentes contra clostridioses comprova sua grande utilização.

Entretanto, apenas as vacinas contra Clostridium chauvoei e Clostridium botulinum são submetidas a controle oficial de potência. Assim, este trabalho teve como objetivo avaliar a eficiência de 13 vacinas polivalentes que continham em sua composição Clostridium novyi tipo $\mathrm{B}$, disponíveis para comercialização no mercado brasileiro.

\section{MATERIAL E MÉTODOS}

Utilizando-se técnicas sorológicas e desafio direto, foram testadas 13 vacinas de 11 laboratórios (Tab. 1), que no ano de 2001 comercializaram no Brasil vacinas polivalentes que continham Clostridium novyi tipo B. Como grupos-controle foram utilizados um toxóide padrão e uma bacterina-toxóide padrão, fornecidos pelo Agriculture Animal Plant Health Inspection Service (APHIS).

Tabela 1. Codificação e composição dos padrões analisados e de vacinas comercializadas no Brasil

\begin{tabular}{|c|c|}
\hline Vacina & Composição \\
\hline T 1 & C. chauvoei; C. septicum; C. novyi; C. sordellii; C. perfringens tipos C e D \\
\hline T 2 & C. chauvoei; $C$. septicum; $C$. sordellii; $C$. novyi tipo B; $C$. perfringens tipos $\mathrm{C}$ e D \\
\hline T 3 & C.chauvoei; septicum; C. sordellii; C. novyi; C. perfringens tipos C e D \\
\hline $\mathrm{T} 4$ & $\begin{array}{l}\text { C. chauvoei; C. septicum; C. perfringens tipos B, C e D; C. novyi; C. botulinum tipos C e D; } \\
\text { C. sordellii }\end{array}$ \\
\hline Т 5 & C. chauvoei; C. perfringens tipos A, B, C e D; C. novyi; C. septicum; C. sordellii; C. haemolyticum \\
\hline Т 6 & C. chauvoei; C. novyi; C. sordellii; C. septicum; C. perfringens tipos B e D \\
\hline T 7 & C. chauvoei; C. septicum; C. sordellii; C. novyi ; C. perfringens tipos C e D \\
\hline Т 8 & C. chauvoei; $C$. septicum; C. novyi tipo B; C. sordellii; $C$. perfringens tipos $\mathrm{B}, \mathrm{C}$ e D \\
\hline T 9 & C. chauvoei; C. septicum;; C. sordellii; C. perfringens tipos B, C e D; C. novyi \\
\hline T 10 & C. chauvoei; C. septicum; C. sordellii; C. novyi; C. perfringens tipos C e D \\
\hline T 11 & C. chauvoei; C. septicum; C. novyi; C. perfringens \\
\hline T 12 & C. chauvoei; C. septicum; C. novyi; C. perfringens tipos B, C e D; C. sordellii \\
\hline T 13 & $\begin{array}{l}\text { C. chauvoei; C. septicum; C. botulinum tipos C e D; C. perfringens tipos B, C e D; C. novyi; } \\
\text { C. sordellii }\end{array}$ \\
\hline IRP-207 & Bacterina toxóide padrão \\
\hline IRP-249 & Toxóide padrão \\
\hline
\end{tabular}
IRP: Internal Reference Protocol.

$\mathrm{Na}$ avaliação sorológica, para cada imunógeno foram utilizados 10 coelhos adultos e seis bovinos com idade entre sete e oito meses. Os coelhos foram vacinados nos dias zero e $21 \mathrm{com}$ metade da dose recomendada para bovinos. Os animais foram sangrados no $35^{\circ}$ dia após a 
primo-vacinação e os soros foram misturados em partes iguais, constituindo-se um pool para cada grupo (Brasil, 1997). Os bovinos, sem histórico de vacinação contra Clostridium novyi tipo B e negativos ao teste de soroproteção em camundongos (Tammemagy, Grant, 1967), foram vacinados com a dose recomendada para a espécie, com reforço aos 42 dias e sangrados nos dias 42 e 56 . Em cada sangria, os soros dos seis bovinos foram misturados em partes iguais, constituindo-se um "pool" para cada grupo. Nos grupos testemunhas a vacina foi substituída por salina estéril a $0,85 \%$. Todos os soros foram mantidos a $-20^{\circ} \mathrm{C}$ até a realização dos testes.

Os pools dos soros dos coelhos e dos bovinos foram submetidos a uma triagem, pela técnica de soroproteção em camundongos, frente a $2,5 \mathrm{DL}_{50}$ de toxina alfa (Tammemagy, Grant, 1967). Os soros que protegeram os camundongos foram titulados pelo método de soroneutralização em camundongos (Brasil, 1997), empregando nível de teste de $\mathrm{L}+/ 100$. Como controle dos testes foi utilizada antitoxina alfa padrão (IRP 298) contendo 490UI/ml.

$\mathrm{Na}$ avaliação por desafio direto, para cada imunógeno foram utilizados dois grupos (I e II) de oito cobaias. Nos grupos-controle, com cinco cobaias cada, a vacina foi substituída por salina estéril a $0,85 \%$. Os animais, vacinados com $1 / 5$ da dose recomendada para bovinos nos dias zero e 21, foram desafiados com $100 \mathrm{DL}_{50}$ de suspensão de esporos de Clostridium novyi tipo B no dia 35. As cobaias do grupo I foram desafiadas com suspensão de esporos padrão (IRP 307) e as do grupo II com suspensão de esporos produzida para o experimento. As cobaias inoculadas foram observadas por 72 horas, registrando-se as mortes ocorridas (Estados Unidos, 1991).

Para produção da toxina alfa, a amostra de referência de Clostridium novyi tipo B (ATCC ${ }^{1}$ 25758) foi cultivada em meio de Cardella (Cardella et al., 1958), em atmosfera de anaerobiose à $37^{\circ} \mathrm{C}$ por 18 horas. A cultura obtida foi centrifugada a $8000 \mathrm{x}$ g por 30 minutos e o sobrenadante concentrado por ultrafiltração com membrana de retenção de $10 \mathrm{KDa}^{2}$. A toxina foi padronizada ao nível de teste de L+/100 (Estados

\footnotetext{
${ }^{1}$ ATCC - American Type Culture Collection

${ }^{2}$ Amicon-Milipore Corporation, USA.
}

Unidos, 2002). A dosagem de proteína foi realizada pelo método de biureto, comparado a curva padrão de soroalbumina bovina pela leitura em densidade ótica a $690 \mathrm{~nm}$ de absorbância em espectrofotômetro. Os esporos foram produzidos a partir da amostra de Clostridium novyi tipo B (ATCC 25758), de acordo com a técnica descrita por Kolbe et al. (1981). A titulação da suspensão de esporos em $\mathrm{DL}_{50}$ foi realizada pelo método de Reed e Müench (1938).

\section{RESULTADOS E DISCUSSÃO}

A padronização da toxina frente a $0,1 \mathrm{UI} / \mathrm{ml}$ de antitoxina alfa padrão foi de $5 \mathrm{~L}+/ 100$, com título de $20 \mathrm{DL}_{50}$ e $0,13 \mathrm{mg}$ de proteína para cada L+/100, superiores aos níveis mínimos exigidos pelo MAPA de $10 \mathrm{DL}_{50}$ e $0,05 \mathrm{mg}$ de proteína. (Brasil, 1997).

Os resultados do teste de eficiência dos imunógenos comerciais, expresso em UI/ml de antitoxina alfa de Clostridium novyi tipo B nos pools dos soros de coelhos, positivos ao teste de soroproteção, são apresentados na Tab. 2.

Tabela 2. Títulos de antitoxina alfa de Clostridium novyi tipo B em "pool" de soros de coelhos $^{1}$ coletados aos 14 dias, após a segunda vacinação $^{2}$ com imunógenos comerciais e toxóide padrão

\begin{tabular}{cc}
\hline Vacina & Antitoxina alfa (UI/ml) \\
\hline T1 & 8 \\
T2 & 2 \\
T5 & 3 \\
T10 & 12 \\
IRP 249 (toxóide padrão) & 15 \\
\hline${ }^{1}$ Positivos ao teste de soroproteção em camundongos. \\
${ }^{2}$ Vacinados nos dias 0 e 21.
\end{tabular}

As vacinas $\mathrm{T} 1$ e $\mathrm{T} 10$ induziram respostas de antitoxina alfa de $8 \mathrm{UI} / \mathrm{ml}$ e $12 \mathrm{UI} / \mathrm{ml}$, respectivamente, e o toxóide padrão IRP 249 de $15 \mathrm{UI} / \mathrm{ml}$, superiores ao nível mínimo de 3,5UI/ml exigido pelo MAPA para aprovação de vacina contra Clostridium novyi tipo B (Brasil, 1997). As vacinas T2 e T5 apresentaram níveis de $2 \mathrm{UI} / \mathrm{ml}$ e $3 \mathrm{UI} / \mathrm{ml}$ respectivamente, abaixo do nível exigido pela legislação brasileira, mas superior ao nível mínimo de $0,5 \mathrm{UI} / \mathrm{ml}$ exigido pelo Code of Federal Regulations (Estados Unidos, 2002). O Brasil adota, para vacinas 
contra clostridioses, os parâmetros preconizados pela British... (1985), ratificados pela European... (1998).

Os pools de soros dos bovinos vacinados com T1, T2, T5 e T10, positivos ao teste de soroproteção, foram submetidos à prova de soroneutralização em camundongos e os títulos de antitoxina alfa são apresentados na Tab. 3 .

Tabela 3. Títulos de antitoxina alfa de Clostridium novyi tipo B em pool de soros de bovinos $^{1}$ coletados aos 42 e 56 dias após a primeira vacinação com imunógenos comerciais, sendo a última coleta feita 14 dias após a segunda vacinação

\begin{tabular}{lcc}
\hline \multirow{2}{*}{ Vacina } & \multicolumn{2}{c}{ Antitoxina alfa (UI/ml) } \\
\cline { 2 - 3 } T1 & Dia $42^{2}$ & Dia $56^{3}$ \\
T2 & 0,1 & 4,0 \\
T5 & 0,1 & 2,0 \\
T10 & 0,1 & 2,0 \\
${ }^{1}$ Positivos ao teste de soro proteção em camundongos. & \\
\multicolumn{2}{l}{ Segunda dose de vacina. ${ }^{3}$ 14 dias após a segunda vacinação. }
\end{tabular}

As vacinas T1, T2, T5 e T10 induziram títulos em coelhos e bovinos (Tab. 1 e 2) e os resultados demonstraram ser a resposta em coelhos superior à obtida em bovinos.

A titulação dos soros dos bovinos, após a segunda dose da vacina (Tab. 2) confirma a necessidade da dose de reforço para se estabelecer imunidade adequada para Clostridium novyi tipo B, conforme demonstrado por Kerry e Graig (1979). Resultados semelhantes foram observados por Azevedo et al. (1998) e Lobato et al. (2000) em vacinas contra Clostridium perfringens tipos C e D.

Macheak et al. (1972) demonstraram, em ovinos, que o título de $1,6 \mathrm{UI} / \mathrm{ml}$ de antitoxina alfa confere proteção ao desafio com suspensão de esporos de Clostridium novyi tipo B. Brown et al. (1976) estabeleceram que os níveis protetores para ovinos são os mesmos dos bovinos e Harbola e Verma (1988) demonstraram, em ovinos, $0,4 \mathrm{UI} / \mathrm{ml}$ de antitoxina alfa como nível mínimo de proteção. Baseando-se nos resultados destes autores, poder-se-ia inferir que os títulos de 2,0UI/ml induzidos pelas vacinas $\mathrm{T} 2$ e T5 (Tab. 3) seriam suficientes para proteger bovinos e ovinos.
A utilização do teste de soroproteção em camundongos para triagem dos soros dos coelhos e bovinos permitiu uma redução significativa no número de animais de laboratório utilizados no experimento. Pela mesma razão, esse teste também foi empregado por Lobato (1989), Azevedo et al. (1998) e Lobato et al. (2000).

A titulação da suspensão de esporos produzida e da suspensão padrão IRP 307 foi de $10^{4} \mathrm{DL}_{50} \mathrm{e}$ $2,4 \times 10^{4} \quad \mathrm{DL}_{50}$, respectivamente. $\mathrm{O}$ nível empregado nos testes foi de $1 \times 10^{2} \mathrm{DL}_{50}$. A suspensão de esporos glicerinada mantida a $70^{\circ} \mathrm{C}$ mostrou-se estável durante a realização do experimento, sendo avaliada por um período de seis meses.

Os resultados obtidos no teste de desafio direto em cobaias para os grupos I e II são apresentados na Tab. 4.

Tabela 4. Teste de eficiência de vacinas que continham em sua composição Clostridium novyi tipo B em cobaias vacinadas e desafiadas com $100 \mathrm{DL}_{50}$ com suspensão de esporos por via intramuscular

\begin{tabular}{lcc}
\hline Vacina & $\begin{array}{c}\text { Grupo I } \\
\text { Vivos/total }\end{array}$ & $\begin{array}{c}\text { Grupo II } \\
\text { Vivos/total }\end{array}$ \\
\hline T1 & $8 / 8$ & $8 / 8$ \\
T2 & $8 / 8$ & $8 / 8$ \\
T3 & $0 / 8$ & $0 / 8$ \\
T4 & $0 / 8$ & $0 / 8$ \\
T5 & $8 / 8$ & $8 / 8$ \\
T6 & $0 / 8$ & $0 / 8$ \\
T7 & $0 / 8$ & $0 / 8$ \\
T8 & $0 / 8$ & $0 / 8$ \\
T9 & $0 / 8$ & $0 / 8$ \\
T10 & $8 / 8$ & $8 / 8$ \\
T11 & $8 / 8$ & $8 / 8$ \\
T12 & $0 / 8$ & $0 / 8$ \\
T13 & $0 / 8$ & $0 / 8$ \\
IRP 207 Bacterina padrão & $8 / 8$ & $8 / 8$ \\
Testemunha (salina $0,85 \%)$ & $0 / 5$ & $0 / 5$ \\
\hline 'Desafio com $1 \times 10^{2}$ de suspensão de esporos padrão IRP \\
307. \\
${ }^{2}$ Desafio com $1 \times 10^{2}$ de suspensão de esporos produzida.
\end{tabular}

Os resultados com o desafio direto em cobaias e os testes de detecção de antitoxina alfa de Clostridium novyi tipo B mostram que as vacinas $\mathrm{T} 1, \mathrm{~T} 2$, T5 e T10, que induziram resposta imunológica em coelhos e bovinos, também protegeram as cobaias frente ao desafio com suspensão de esporos. A vacina T11 protegeu as cobaias no teste de desafio direto, mas não induziu nível de antitoxina alfa detectável nos 
coelhos e bovinos, sugerindo tratar-se de uma bacterina. A inclusão do teste de desafio direto em cobaias, neste trabalho, está diretamente relacionada à falta de informação nos rótulos das vacinas analisadas, os quais, em sua maioria, indicam apenas tratar-se de vacina inativada.

Considerando que os efeitos sobre o organismo causado pelo Clostridium novyi tipo B estão relacionados à ação direta da toxina alfa, um toxóide deverá ser preferencialmente indicado para prevenção.

$\mathrm{Na}$ última década, foram lançadas vacinas com maior número de componentes clostridiais. Das 13 vacinas analisadas, apenas quatro foram registradas entre 1980 e 1990; as outras nove obtiveram o registro a partir de 1995 (Sindan, 2003). Provavelmente, a apressada competição por um mercado emergente leve os laboratórios produtores a lançarem novas vacinas polivalentes contra clostridioses, mesmo na ausência de diagnóstico e estudos epidemiológicos de prevalência dos agentes que compõem essas vacinas.

O controle oficial das vacinas contra Clostridium chauvoei implantado no Laboratório Regional de Apoio Animal do MAPA-RS (LARA/RS) e das vacinas contra Clostridium botulinum $\mathrm{C}$ e $\mathrm{D}$, no Laboratório Regional de Apoio Animal do MAPA-MG (LARA/MG), em 1994, permitiu maior rigor na garantia da qualidade desses produtos. Os resultados obtidos por Lobato (1989), ao avaliar vacinas comerciais contra botulismo, contribuíram, decisivamente, para a implantação do controle oficial desse imunógeno (Mota, P.M.P.C. informação verbal) ${ }^{3}$.

Ressalta-se que mesmo sem a implantação do controle oficial de todos os componentes das vacinas contra clostridioses, a Lei 8.078 (Brasil, 1990), consagrada como Código de Defesa do Consumidor, estabelece clara responsabilidade do fabricante pela qualidade de seus produtos e que a Portaria 301 (Brasil, 1996), do MAPA, em seu Artigo 21 exige que toda partida de produto biológico, antes da comercialização, deverá ser submetida, conforme o caso, aos seguintes controles: esterilidade, pureza, inocuidade, eficácia, sorologia, potência/imunogenicidade.

${ }^{3}$ Laboratório Regional de Apoio Animal, LARA MG, Cx P. 50, 33600-000, Pedro Leopoldo-MG
O trabalho conduzido por Lobato (1989), que estudou vacinas contra botulismo, as avaliações de vacinas contra Clostridium perfringens tipos C e D realizadas por Azevedo et al. (1998) e Lobato et al. (2000), a avaliação de vacinas contra Clostridium sordellii por Balsamão (2001) e o presente experimento com Clostridium novyi tipo B demonstraram que, em sua maioria, as vacinas contra clostridioses não induzem respostas imunes adequadas contra os agentes das enfermidades que informam prevenir.

\section{CONCLUSÃO}

Os resultados obtidos neste estudo somam-se aos já relatados e indicam a necessidade urgente de controle efetivo das vacinas contra Clostridium novyi tipo B.

\section{REFERÊNCIAS BIBLIOGRÁFICAS}

AZEVEDO, E.O.; LOBATO, F.C.F.; ABREU, V.L. et al. Avaliação de vacinas contra Clostridium perfringens tipos C e D. Arq. Bras. Med. Vet. Zootec., v.50, p.239-242, 1998.

BALDASSI, L. Isolamento de bactérias do gênero Clostridium e detecção de toxina botulinica a partir de materiais obtidos de bovinos com suspeita clínica de botulismo. 1986. 59f. Dissertação (Mestrado) - Faculdade de Saúde Pública, Universidade de São Paulo, São Paulo.

BALSAMÃO, G.M. Teste de potência para Clostridium sordellii em vacinas comerciais contra clostridioses. 2001. 25f. Dissertação (Mestrado em Medicina Veterinária) - Escola de Veterinária, Universidade Federal de Minas Gerais, Belo Horizonte.

BRASIL. Lei no 8.078, 11 de setembro de 1990. Diário Oficial da União, Brasília, 12 de setembro de 1990. Suplemento no 176.

BRASIL. Ministério da Agricultura. Portaria n. 301, 19 de abril de 1996. Diário Oficial da União, Brasília, 25 de abril de 1996. Seção 1, p.7013-7018.

BRASIL. Ministério da Agricultura. Portaria n. 49, 12 de maio de 1997. Diário Oficial da União, Brasília, 16 de maio de 1997. Seção 1, p.1016810169. 
BRITISH Pharmacopeia (VETERINARY). Veterinary Vaccines. Departament of Health and Social Security, Medicines Commission. Reino Unido. 1985.

BROWN, K.K.; PARIZEK, R.E.; STEWART, R.C. Prevention of clostridial disease in catle and sheep by vaccination with a multivalent bacterintoxoid. Vet. Med. Small Anim. Clin., v.12, p.1717-1720, 1976.

CARDELLA, M.A.; DUFF, J.T.; GOTTFRIED, C. et al. Studies on immunity to toxins of Clostridium botulinum. J. Bacteriol., v.75, p.360$365,1958$.

ESTADOS UNIDOS. Code of Federal Regulations. Washington: office of the Federal Register National Archives and Record Administration, Clostridium novyi bacterintoxoid, sec. 113.108, p.517, 1991.

ESTADOS UNIDOS. Code of Federal Regulations. Washington: office of the Federal Register National Archives and Record Administration, sec. 113.108, v.1, 2002. Clostridium novyi bacterin-toxoid. Disponível na Internet via www.URL: http://a257.g.akamaitech.net/7/257/2422/14mar2 0010800/edocket.access.gpo.gov/cfr_2002/janqtr $19 \mathrm{cfr} 113.108 . \mathrm{htm}$. Acesso em 02 de abril de 2002.

EUROPEAN Pharmacopeia. 3.ed. Sainte Ruffine: Maisonneuve S.A., 1998. p.167: Veterinary Antisera and Veterinary Vaccines.

HARBOLA, P.C.; VERMA, J.G. Immunogenic response to Clostridium novyi type B toxóide in guinea pigs and sheep. Indian Vet. J., v.8, p.658$660,1988$.

KERRY, J.B.; CRAIG, G.R. Field studies in sheep with multicomponent clostridial vaccines. Vet. Rec., v.105, p.551-554, 1979.

KOLBE, D.R., CLAUS, K.D.; NERVIG, R.M. A method for the production of Clostridium haemolyticum spores on solid medium. J. Biol. Stand., v.9, p.115-119, 1981.

LOBATO F.C.F.; MORO, E.; UMEHARA, O. et al. Avaliação da resposta de antitoxinas beta e épsilon de Clostridium perfringens induzidas em bovinos e coelhos por seis vacinas comerciais no Brasil. Arq. Bras. Med. Vet. Zootec., v.52, p.313318, 2000.

LOBATO, F.C.F. Avaliação de imunógenos antibotulínicos em uso no Brasil. 1989. 59f. Dissertação (Mestrado). Escola de Veterinária, Universidade Federal de Minas Gerais, Belo Horizonte.

MACHEAK, M.E.; CLAUS, K.D.; MALOY, S.E. Potency testing Clostridium novyi containg bacterins: comparison of immunologic response in guinea pigs and sheep. Am. J. Vet. Res., v.33, p.1201-1208, 1972.

REED, L.J.; MUENCH, H. A simple method of estimating fifty per cent endpoints. Am. J. Hyg., v.27, p.493-497, 1938.

ROBLES, C.A.; KERBAGE, O.K.; MOREIRA, A.R. Hepatitis Infecciosa Necrosante en ovinos Merino de la Patagonia Argentina, parasitados con Thysanosoma actinioides. Arch. Med. Vet., v.32, p.125-133, 2000.

SINDAN. Sindicato Nacional da Indústria de Produtos Veterinários: Manual de Produtos Veterinários 2003-2004. Robe Editorial, 2001. $1106 \mathrm{p}$.

STERNE, M.; BATTY, I. Clostrídios patógenos. Zaragoza: Acribia, 1978. 135p.

TAMMEMAGY, L.; GRANT, K.M. Vaccination in the control bovine botulism in Queensland. Aust. Vet. J., v.43, p.368-373, 1967.

UZAL, F.A.; OLAECHEA, F.V.; VANNELLI, S.A. Un caso de hepatitis infecciosa necrosante en oveja sin Fascíola hepática. Rev. Med. Vet., v.77, p.377-379, 1996. 